\title{
Un laberinto para jugar a la soledad: «La casa de Asterión»'
}

\author{
Jorge Ramírez Caro \\ Universidad Nacional de Costa Rica \\ Universidad de Costa Rica
}

Lo que importa es la correspondencia de la casa monstruosa con el habitame monstruoso. El Minotauro justifica con creces la existencia del laberinto.

Jorge Luis Borges

Debe haber algo misterioso en el espacio casa para que sea tan frecuentado en las producciones literarias de todos los rincones del mundo: no existe pueblo que no cuente con una donde se deleiten y se encarnen los fantasmas de todas las edades. Basta echar un vistazo a los títulos de textos de gran impacto en la comunidad lectora para darse cuenta de que la casa es una de las estaciones más recurrida entre los escritores: Casa de campo, de Donoso; La casa de los espíritus, de Allende; Casa tomada, de Cortázar; La caída de la Casa Usher, de Poe; y «La casa de Asterión», de Borges. En otros textos, como María, de Isaacs y Cien años de soledad, de García Márquez, este espacio funciona como eje alrededor del cual gira toda la trama y sin la cual el mundo narrado se quedaría sin centro sobre el que gravitar, dado que allí converge todo lo que acontece en el resto del universo y por lo

!. Este articulo pone de relieve la reescritura que Borges ha realizado sobre textos anteriores de la radición cultural occidental y la imagen del Minotauro: en lugar de presentársenos como un ser despreciable. el monstruo es humanizado y propuesto de manera que nos hace solidarizarnos con aquel que tradicionalmente se nos ha mostrado como verdugo y enemigo de la humanidad. La imagen del dobla y del laberinto tratada nos permite adentrarnos en nuestro propio ser $y$ descubrimos ese orro que nosotros mismos y los demás despreciamos y desprecian. 
que sucede allí es que el mundo sigue su curso. En La casa de Bernarda Alba, de García Lorca, y La casa, de Daniel Gallegos, por ejemplo, es la casa como poder, autoridad y tradición lo que vertebra la trama de estos textos dramáticos. Pero no existe la casa como isla, sin esa relación necesaria con otras casas, razón por la cual tenemos también Casas vecinas, de Castro, cuyo planteamiento central es el de parangonar y contraponer lo que sucede en una casa profana como lo es un prostíbulo con lo que acontece en una casa sagrada, como lo es un convento. Sería bueno echarle un vistazo analítico e interpretativo a la función de este espacio, no sólo en los títulos, sino más allá de los umbrales del texto.

Para mi ejercicio de lectura me he quedado con «La casa de Asterión», de Borges, texto del que el lector encontrará un anexo al final $^{2}$. He escogido este relato porque él también me ha elegido de manera ineludible: yo quería una casa donde refugiar mi pena y $\mathrm{mi}$ soledad, leer y leerme. Quise llegar a la de Cortázar pero ya estaba tomaba, quise pasarme a la de Poe pero se había caído. Casa de campo de Donoso me pareció lejana y supuse muy trillada La casa de los espíritus de Allende. Entonces me entregué a este universo laberíntico que es la casa de esta bestia que el destino ha terminado de hundir en las manos de Teseo, pero que Borges ha rescatado de los tentáculos de la racionalidad para of recernos ese lado familiar, humano y tierno que todos llevamos escondido bajo el universo de las palabras. De este modo el texto cumple su efecto al afectarme. Después de haber leído el texto varias veces = después de que el texto me ha leído varias veces, me permitiré ordenar mi propio recorrido para ver si, perdido donde estoy, puedo perder a otros u otros puedan encontrarme. El hilo que elijo para guiarme por este laberinto es el de entregarme al recorrido del texto. desde la primera hasta la última línea, con paradas en aquellos aspectos que me sirvan para leer y leerme, pescar y pescarme, escribir y escribirme-inscribirme.

2. Jorge Luis Borges. El Aleph (1949) (Buenos Aires: Emecé / Alianza Editorial. 1994) 69-72. 


\section{El título}

Lo primero sobre lo que me detendré será el título. En él encuentro dos elementos: uno familiar (casa) y otro extraño (Asterión), unidos por una preposición que los aproxima y a la vez los distancia, dado que puede indicar la contextura de la casa como la pertenencia o posesión por parte de Asterión, lo cual hace presuponer que éste posee rasgos humanos. De no ser así, puedo decir que lo cotidiano y familiar es asumido por lo raro y extraordinario, produciéndose un efecto ominoso. Este efecto se acentúa cuando exploramos el texto y nos damos cuenta de que la casa adquiere la dimensión de mundo-universo y Asterión la de Minotauro-monstruo. Esto es, los elementos familiar y extraño aparecen como dobles de otros elementos anclados en el texto de la cultura: la casa es el doble del universo y Asterión el del Minotauro.

Ambos elementos, no sólo se desdoblan y nos permiten una lectura circular, sino que también nos posibilitan leer el texto desde otro texto, desde el mito del Minotauro, en el que se condensan las imágenes de hombre y toro. De este modo, si Asterión es el Minotauro, entonces, la casa es el laberinto. De donde resulta que desde el principio se nos va a dar un juego de espejos que duplicará los elementos que intervienen, hasta el punto de volver familiar lo extraño y extraño lo familiar. En este sentido, Asterión aparece desde el título como un ser doméstico y humanizado que rompe con la imagen que la tradición literaria clásica ha impuesto sobre el Minotauro, ser monstruoso y subyugador del pueblo ateniense.

Este título enmarca el texto como producto de un juego: la literatura surge al interior de la literatura, si nos atenemos a la referencia mitológica que tiene Asterión ${ }^{3}$. Aquí se pone de relieve lo propio de

3. Asterión seviala el origen y naturaleza celeste del toro monstruoso. Según la mitología. el dios se presenta bajo la forma de un toro marcado en la frente por la roseta solar, mientras la diosa se concibe como diosa madre y aparece identificada con los cuernos de la luna. Minos y Pasífae revelan la misma naturaleza astral: el rey Minos es fruto de la unión del toro celeste (Zeus) y Europa ( "la de amplia visión»). Pasífae. cuỵo nombre significa "la que brilla para todos. la 
la producción literaria de Borges: su literatura es una literatura dentro de otra, cuestión que pone de manifiesto no sólo el carácter fantástico de su producción, sino también su naturaleza de artificio. El mismo Borges ha señalado que este tipo de literatura pone en juego cuatro procedimientos básicos: a) el texto como producto de otro texto; b) la fusión realidad y sueño; c) el viaje en el tiempo; y d) el doble. Cualesquiera de estos procedimientos son muy recurridos por el autor en toda su producción literaria. En el caso que nos ocupa, vemos que su relato aparece como la transcripción de un texto previamente existente. Este mecanismo se refuerza con el epígrafe y con la nota aclaratoria en la que juzga conveniente usar infinitos por el catorce de la versión que reelabora. De nuevo entra a circular el juego del doble: Borges, escritor y transcriptor al mismo tiempo, cumple un papel de crítico literario.

\section{El epígrafe y la cita}

Estas marcas refuerzan el carácter del texto en el texto aludido en el título y nos sitúan más concretamente en la versión de donde procede la historia que se nos va a contar. El epígrafe, además de señalar el origen regio de Asterión, apunta hacia el origen libresco del texto de Borges y nos coloca frente a otro de los juegos a los que nos va a enfrentar el texto: el del escritor que ahora se convierte en crítico literario y en transcriptor. No sólo suprime la cifra catorce, sino que interpola a su lado, entre corchetes, la conjetura infinitos en varias partes del texto. Catorce no sólo es el doble de siete, sino que sugiere el simbolismo mágico de los números y letras de la tradición cabalística judía y pitagórica, muy frecuentada por el escritor. La elección infinitos, por el contrario, se aparta de esta mística y deriva hacia una creencia en la infinitud del espacio y del tiempo, concepción que,

que es visible a todos", epíteto asimilable a la luna. es hija de Helios. el sol. La versión mitológica sería la trasiación fabulada del ritual hierogámico de la unión toro-sol (Minos) con la vaca-luna (Pasífae), con el fin de crear vida nueva, el Minotauro, ser híbrido de dios (toro) y rey (Minos). M. C. Howatson. Diccionario abreviado de la literatura clásic a (Madrid: Alianza Editorial. 1999). 
como veremos, es clave en la lectura del texto. De acuerdo con lo anterior, la presente es una historia consignada en otra parte, en otro tiempo y para otro público-lector. Pero como el mismo Borges ha dicho, citando a Schopenhauer: «Nadie ha vivido en el pasado, nadie vivirá en el futuro; el presente es la forma de toda vida, es una posesión que ningún mal puede arrebatarle», entonces, la historia de Asterión es una cuestión del presente, del ahora y para nosotros (no se olvide la alusión a la Biblioteca, asunto central en la producción textual de Borges $)^{4}$. De este modo, este procedimiento no sólo familiariza y humaniza lo extraño, sino que también nos aproxima a ello.

El epígrafe «Y la reina dio a luz un hijo que se llamó Asterión» justifica el título y anticipa la raigambre mitológica de la historia que sigue. Este epígrafe condensa, por omisión, toda una trayectoria narrativa que el lector debe reconstruir: el origen de Asterión de la relación toro-Pasífae. Este tipo de relato puede reconstruirlo cualquier lector que pueda ingresar en el circuito de la tradición mítica en la que se encuentra el origen regio de Asterión. Las marcas Asterión, Apolodoro y Biblioteca nos remiten al mundo de la Antigüedad grecolatina y a un contexto vagamente mitológico que nos lleva a relacionar, como ya hemos adelantado: a) a Asterión con el Minotauro, ser monstruoso, híbrido de hombre y toro y a la casa mencionada con el laberinto cretense construido por Dédalo; b) a la reina con Pasífae, esposa de Minos y amante del toro enviado por Poseidón; y c) a Apolodoro, por último, con el autor a quien la tradición atribuye un compendio tardío, presumiblemente posterior al 60-61 a. C., conocido con el título de Biblioteca, y que incluye las principales leyendas y mitos de la Antigüedad relatados sucintamente.

Tanto el título como el epígrafe enmarcan el monólogo que posteriormente sigue. Esto es, la voz de otro sirve de marco para la

4. En Elogio de la sombra señala: "Que otros se jacten de las páginas que han escrito; a mi me enorgullecen las que he leído». Y en Historia de la noche apunta: “¿Me sera permitido repetir que la biblioteca de mi padre ha sido el hecho capital de mi vida? La realidad es que nunca he salido de ella. como no salió nunca de la suya Alonso Quijanom. 
aparición de la voz del sujeto. Este marco guarda relación con el tema del fantasma ${ }^{5}$ en la tradición psicoanalítica: enmarca y vela al mismo tiempo, protege al sujeto de ese otro monstruoso y nosotros nos acercamos al sujeto con familiaridad. Gracias a ese fantasma nosotros podemos disfrutar la presencia, no monstruosa, sino humana, de la versión de Borges sobre el hombre-toro. En este sentido, en este siniestro se alternan el efecto y el afecto. Las primeras dudas que como lectores estamos prestos a formularnos son: ¿Por qué sólo se mencionan la madre y el hijo? ¿Qué pasó con el padre? ¿Acaso el padre es el tema bordeado? ¿Cómo se origina ese hijo? ¿Qué causa el silencio sobre ese tema? No pretendo responder todas estas preguntas, pero al menos deseo bordearlas con otras palabras que no dirán la verdad.

\section{Estructura}

Veamos ahora el problema de la organización del texto. Tanto el título como el epígrafe están en una voz narrativa distinta de la que encontramos en el monólogo de Asterión, pero igual al cierre del texto. Esto es, encontramos un monólogo en primera persona enmarcado por la tercera persona. Estas tres partes del texto se refieren a tres momentos distintos de la vida de Asterión: el pasado (marcado por verbos como dio y llamó), el presente (marcado por verbos como sé, salgo, soy) y el futuro (marcado por verbos como castigaré, será). Pero también estas partes las podemos ver como el origen, la existencia y la muerte del hombre-toro. Las voces que enmarcan el monólogo son humanas, mientras que las de Asterión son humanizadas. Las palabras del epígrafe y las que aparecen después del monólogo son palabras que cuentan sobre el sujeto, mientras que en el monólogo el sujeto se expresa, cuenta su propio relato. Después del monólogo, sólo en las palabras del título encontramos una humanización de Asterión, al llamarse a su espacio de reclusión casa y no laberinto.

5. Cfr. Danièle Silvestre. «El fantasma». AA.VV.. Aspectos del malestar en ia cultura (Buenos Aires: Manantial. 1989) 74-79. 
Esta estructura nos sirve para ver la relación que existe entre la primera y la última parte: tanto el principio como el final están circunscritos por una omisión o silencio. El tex to emerge de y desemboca en un hecho que no se cuenta: cómo fue el origen de Asterión y cómo fue su muerte. En otras palabras, al principio el texto bordea el padre y al final la muerte. Construido a partir de la omisión, la alusión y el enigma, todo este artificio sólo sirve para que la palabra omita-cierna la verdad: lo que está por fuera es el padre y la muerte, modelos pulsionales señalados por Freud. Lo traumático y lo espantoso están bordeados o umbilicados.

\section{El monólogo de Asterión}

El monólogo está organizado en cinco párrafos. Si leemos el texto por primera vez, nos percatamos de que quien habla es Asterión, no hasta el final de su monólogo, sino hasta el final del relato, a través de la sustitución de su nombre por el de Minotauro: una vez que nos hemos identificado con la bestia, interviene una tercera persona y nos hace recordar el carácter abominable del ser que acaba de ser sacrificado. Contrario a las narraciones previas — que lo refieren o cuentan-, aquí se nos presenta su propia voz hablando de sus propias desgracias, peripecias, angustias y esperanzas: Asterión (se) cuenta y nos cuenta. Terminado el relato, el lector se sorprende cuando descubre que lo leído es un fragmento de la autobiografía del Minotauro. Mediante esta palabra Asterión tramita su abandono, su soledad y su dolor de ser un extraño libre y recluido al mismo tiempo. En una segunda lectura sabemos que el primer párrafo abre con la voz de Asterión que rebate o desmiente las acusaciones del otro que lo configura como un ser extraño: soberbio, misántropo, loco, recluido en una casa de tamaño infinito, sin un solo mueble, de puertas abiertas y sin cerraduras. Si comparamos esta primera entrada con el epígrafe, nos damos cuenta de que estamos ante un hijo regio, maldito, rechazado y recluido por sus padres por temor a que se cierna sobre ellos alguna maldición, como en el caso de Edipo o de Segismundo. Contrario 
a las versiones sobre el Minotauro, Asterión nos dice que ha podido salir del laberinto y caminar por la calle hasta el templo de las Hachas y comprobar inocentemente que es temido, creyendo que es por su origen regio, razón que le impide mezclarse con el vulgo. Esta impostura simbólica lo separa de lo real.

Asterión no se reconoce como monstruo. Son los otros los que lo configuran como tal: «La gente oraba, huía, se prosternaba; unos se encaramaban al estilóbato del templo de las Hachas, otros juntaban piedras. Alguno, creo, se ocultó bajo el mar». Aquí se sintetizan las reacciones posibles de la gente frente a Asterión. Pero ese mismo temor que experimenta la gente frente a Asterión, lo ha experimentado él frente a sus rostros: «si antes de la noche volví, lo hice por el temor que me infundieron las caras de la plebe, caras descoloridas y aplanadas». Estamos frente a un rechazo y un temor mutuo, pero por causas distintas: la diferencia del otro espanta en quien la percibe. Ambos lados se ven como extraños y no familiares, excluyentes y no asimilables. Asterión confronta su propio fantasma. No es que quiera ser como los otros: es que no es como ellos y se sabe también distinto. Asterión no sólo tiene la certeza de que lo acusan, sino que también se cree superior a los demás y no establece lazos sociales con quienes considera inferiores.

\section{El problema del doble}

En «La casa de Asterión» se da una correspondencia entre el espacio y el habitante: ambos materializan la soledad y la incomunicación, son prisionero y prisión, porque se traducen en laberinto y Minotauro. Ambas realidades se justifican y reclaman, porque son una y la misma cosa, según nos ayuda a decir Borges en el epígrafe con que acompaño mi lectura. La casa-laberinto es el doble de Asterión-Minotauro. El laberinto encuentra su explicación en el habitante para el que ha sido diseñado y éste, el ser monstruoso. se refugia sin remedio en una construcción que le mantiene con vida al precio del ocultamiento. El lugar que Asterión habita no es sino prolongación 
de sí mismo, ser extraviado en el dolor y la locura, interiores en sombra, confusas galerías, ser nostálgico de vida pero incapaz de ella, no puede salir de su encierro porque afuera no encuentra un rostro en el que identificarse: la diferencia de los otros también le causa terror. Para él, el laberinto no es sólo el lugar donde se recluye, sino también el mundo que lo incluye. Es más, está más seguro en el laberinto donde tiene otro con el que juega que en la calle donde los rostros le causan pavor y está expuesto al temor, al rechazo de y al lapidamiento por los otros. Por eso tiene que volver sobre sus propios pasos para refugiarse en la matriz de su casa-madre.

Asterión es un ser solo porque sólo reconoce al otro simbólicamente, en el juego. Lo real se le vuelve inaceptable e inexplicable. Para evitar su caída definitiva, Asterión se refugia en la soberbia, rechazando a quienes lo rechazan: podría decirse que la soberbia funciona como el fantasma que lo protege de la destrucción y le ayuda a soportar el aislamiento y la soledad. Al considerarse único, como único también es su espacio, menosprecia a los otros tanto como los otros lo desprecian a él. Mientras que él es único, los demás son idénticos entre sí, pero diferentes a él. Lo regio frente a lo diverso, agrupado bajo términos como la gente, la grey, la plebe y el vulgo. Frente a los otros, Asterión resalta su origen regio que lo singulariza. Al refugiarse en ese origen, en su diferencia, se convierte en un ser de la soledad, de la insociabilidad: desprecia a los demás y desprecia inmediatamente la posibilidad de lenguaje con ellos: «No me interesa lo que un hombre pueda transmitir a otros hombres; como el filósofo, pienso que nada es comunicable por el arte de la escritura» ${ }^{6}$. Aquí es donde Asterión se aparta de lo humano.

6. En su «Elogio de Helena». Gorgıas se refería al poder de la palabra en los siguientes términos: "La palabra es un poderoso tirano. capaz de realizar las obras más divinas, a pesar de ser el más pequeño e invisible de los cuerpos. En efecto. es capaz de apaciguar el miedo y eliminar el dolor, de producir alegria y excitar la compasión... No hay ser, si lo hubiera. no podría ser conocido: si fucra conocido. no podria ser comunicado su conocimiento por medio del lenguaje» (Fragmentos y reximomos, Madrid: Aguilar. 1966) 87. 
Asterión no se integra porque no puede salir de su esfera narcisista de autorreconocimiento y autocontemplación de su unicidad y superioridad frente a los otros. Al renunciar al lenguaje renuncia a toda posibilidad de dar cabida al otro. Lo único que conocemos es su monólogo que, por el efecto de escritura, se convierte en un relato para nosotros, mediado por el escritor-transcriptor que no puede entablar conversación con él. El rechazo del lenguaje es una reclusión en sí mismo, en el silencio de la soledad donde vagará como en un laberinto, razón por la que, como insinuamos antes, posee un carácter psicótico. Asterión mismo es un laberinto: nadie puede entrar en él porque se pierde sin esas redes que teje el lenguaje y también todo el que entre en su espacio se pierde por el intrincado mundo de caminos y vericuetos que lo llevan a sus propias garras. Sin lenguaje, Asterión se reduce exactamente a lo que dicen los otros de él: soberbia, misantropía y locura. Desprecia su único hilo de salvación y se queda con la esperanza de otro superior a él que venga a redimirlo. ¿De qué desea ser salvado Asterión? ¿De la soledad, de la soberbia, de la misantropía, de la locura, de sí mismo?

El laberinto en el que está sumido Asterión no es tanto físicotemporal, sino psicológico, psicótico: es prisionero de sí mismo, está encerrado en sí mismo. Está perdido en el laberinto de su propio yo. Esto empata con lo que hemos dicho desde el mismo título y al referirnos a la correspondencia entre la unicidad de la casa y de Asterión mismo: Asterión es su propio laberinto. A este laberinto le hace falta todo lo humano cultural: no tiene lenguaje ni muebles, es una estructura vacía de significantes. Lo único que posee esta armazón son vueltas y revueltas, galerías y bifurcaciones, encrucijadas y repeticiones, sombras y fantasmas. Tal vez exagero si señalo que este laberinto es una imagen del aparato psíquico. El no poder establecer contacto con el otro a través del lenguaje, sino a través de los sacrificios, hace desembocar a Asterión en la locura y en la soledad en una «casa del tamaño del mundo». La casa está hecha a su imagen y semejanza, es una reproducción del universo, el laberinto por excelencia dentro de 
la producción textual de Borges: «Todas las partes de la casa están muchas veces, cualquier lugar es otro lugar»? ${ }^{7}$.

«La casa de Asterión» nos of rece un nuevo aspecto del tema del doble: el laberinto ahora es el yo, envuelto en la concepción del universo y del tiempo como laberinto donde todo se repite: «Todo está muchas veces, catorce veces, pero dos cosas hay en el mundo que parecen estar una sola vez: arriba, el intrincado sol; abajo, Asterión. Quizá yo he creado las estrellas y el sol y la enorme casa, pero ya no me acuerdo». Asterión tiene la sensación de existir desde toda la eternidad como creador de lo existente. Quizá Asterión fue un dios que se olvidó de serlo en el laberinto de la eternidad y ha venido a recaer, tras infinitas identidades, en el Minotauro. «He olvidado los hombres que antes fui», dice Asterión en el poema «El laberinto». O tal vez Asterión no ha dejado de ser nunca él mismo en esa eternidad donde está sumido. Es probable que este olvido esté relacionado con la represión, porque apunta directamente a lo que hemos señalado sobre el padre y la muerte como elementos bordeados por el texto.

¿Por qué Asterión ha hecho del laberinto su refugio personal en el que todo se le repite trágicamente, de donde no puede salir sin desear otra cosa que la llegada del Otro que jugará con él o del otro que lo redimirá, pero que al mismo tiempo se convertirá en su propio verdugo? Nada lo libera de lo que desea ser liberado, porque nunca habla con nadie y nadie puede interpretar su deseo. Asterión es un ser nacido para ocultarse y matar, esperar y ser asesinado. Es un ser regio pero bestia temida por todos. La muerte que da a otros para redimir al pueblo de su bestialidad, es la muerte que recibirá después para

7. Borges exploró de muchas maneras el problema del laberinto, tanto en cuentos como en poemas. Para él. el espacio. el tiempo. la memoria. el acto de creación, la búsqueda de inmortalidad y la inmortalidad misma. la muerte y sus sucesivas reencarnaciones. el universo entero y su conocimiento, todo es laberinto. Rastrear este tema, aún es la obra incompieta de Borges, es ya entrar en un laberinto. Véanse de Elogio de la sombra: "El laberinto», "Laberinto" y "Heráclito»; de Los con jurados: “El hilo de la fábula» y «Laberinto»; de Ficciones: «El jardín de los senderos que se bifurcan» $;$ “La Biblioteca de Babel», por señalar los más evidentes textos sobre el laberinto en este autor. 
redimirse a sí mismo de su propia vida laberíntica: la muerte se presenta como su propia salvación.

Otro aspecto de la alteridad que podemos considerar es al otro como semejante: ese otro que soy yo, ubicado en el registro de lo imaginario. Ese otro entra en la escena del yo por medio del juego: «Pero de tantos juegos el que prefiero es el de otro Asterión. Finjo que viene a visitarme y que yo le muestro la casa». El juego nos remite al juego presencia / ausencia de la madre. Este juego también cumple el papel del fantasma al sostener la realidad del yo: encubre la falta en el otro. Lo que le falta al yo el juego se lo proporciona con un doble imaginario con el que comparte su propio mundo. Esto pone en juego también la captura narcisista ${ }^{8}$. Es este Otro imaginario el que hace contrapeso a las caras y miradas horrorizadas de los de la calle.

Finalmente, tenemos el doble real materializado en el redentorverdugo de Asterión, quien no tiene idea de cómo puede ser su salvador: «¿Cómo será mi redentor?, me pregunto. ¿Será un toro o un hombre? ¿Será tal vez un toro con cara de hombre? ¿O será como yo?». El otro que entra en juego es el doble igual o diferente. Las alternativas no sólo son toro u hombre, sino también la conformación de lo que Asterión es: toro con cabeza de hombre u hombre con cabeza de toro como él. La identidad no es sólo consigo mismo sino también con la diferencia. Pero esto es apenas una conjetura, está sólo en el plano de sus dudas. Esa duda lo salva mientras monologa. Suponemos que una vez que identifica al vengador del pueblo con su redentor, al creer que en lugar de matarlo viene a redimirlo, se produce su caída. Esa certeza lo mata. Por esta razón Teseo no encuentra en Asterión resistencia alguna.

Teseo aparece como el vengador de los atenienses, pero Asterión lo acoge como su redentor. Asterión desea y espera al Otro, a quien lo redimirá: del mismo modo como «Cada nueve años entran

8. Roland Chemama (dir.), Diccionario del psicoanálisis (Buenos Aires: Amorrortu Editores. 1996) 69. 


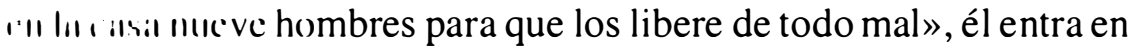

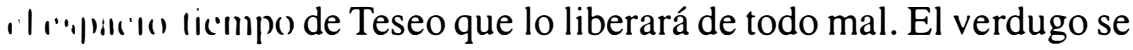
. alılılinl / le liss identidades, la duplicidad del ser que fluye de una a otra

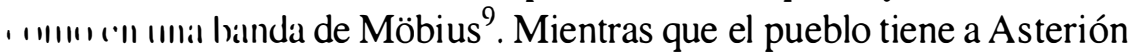
111111 11 verdlugo y su asesino, Asterión se concibe como el que libe-

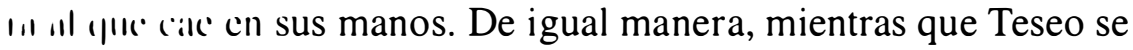
r riliklial cl verdugo de Asterión, el lector lo acompaña en el monó-

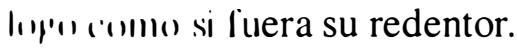

I al pregunta que nos planteamos antes: ¿De qué lo redime la IIII!ll.", sc acerca a su respuesta por medio de esta otra pregunta: . A 11 (') la inexistencia no hay laberintos? Y si no existen laberin111. , Iillupoco hay Asterión?: «uno de ellos [de los jóvenes entregallw. a sillrilicio] profetizó, en la hora de su muerte, que alguna vez II'1:"1'11 mi redentor. Desde entonces no me duele la soledad, porque " "11' vive mi redentor y al fin se levantará sobre el polvo... Ojalá III' Il''l'' " IIII lugar con menos galerías y menos puertas» (el destaca1111.3 $1111(1)$. Este es el deseo de Asterión: la muerte para liberarse del l.111111llu y de sí mismo porque él también es el laberinto, el uno no rivile sill cl otro.

1) nuevo estamos ante la identificación que hemos adelantado inll. Aslcrión y el laberinto. El habitante es a la casa como la casa es il lialinlintc, del mismo modo que el cielo es espejo de la tierra y la I111ir alcl ciclo. Al quebrarse la palabra que sostenía al propio Aste11111. al ccrrar éste su monólogo, se derrumba todo su edificio. El ilincio es el anuncio de la muerte o la muerte misma. El hilo del

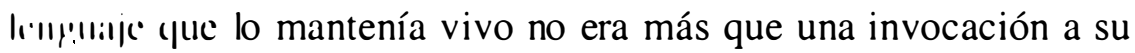

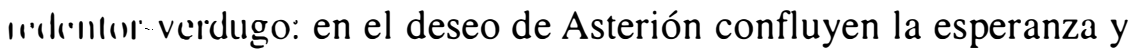
.1 IIII k loclo. La caída de la palabra (aún no encuentro las palabras

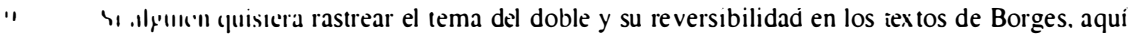
.11.111 unus cuantos ejemplos. «Everything and nothing», «La trama», «La forma de la espa1.1... . I I Imucrtc y ı brújula». «El tema del traidor y del héroe», «Los teólogos» y «El hombre 1.11 (1) IIII) rial" 
para decirlo) de Asterión posibilita la irrupción triunfal de Teseo que se asombra de la no resistencia del Minotauro: «- ¿Lo creerás, Ariadna? —dijo Teseo-. El Minotauro apenas se defendió». Ya no estamos en aquel tiempo y en aquel espacio, ya no estamos ante un lenguaje que se sostenía en la mente de Asterión, sin interlocutor posible. Estamos ahora ante la transmisión de un acontecimiento del que también el texto ha guardado silencio: la muerte. Se imponen lo humano y la cultura (Teseo y su espada), el lenguaje y la socialización con el otro (Teseo y Ariadna), frente a la soberbia, la misantropía y la locura de Asterión.

Enfatizo la estrecha relación entre el tema del laberinto con el del doble: funciona como una metáfora que revela la pérdida de un centro. Asterión sale a la búsqueda de ese centro, ámbito de paz y perfección que le permitirá alcanzar su redención. Sale de su laberinto para entrar en el mundo, donde no la encuentra, y regresa a su laberinto, a sí mismo, donde tampoco la halla. De este modo, su vida se transforma en un laberinto donde el pasado, el presente y el futuro se fusionan y se convierten en otro laberinto y el texto mismo se transforma para el lector en otro laberinto en el que las palabras funcionan como el hilo de Ariadna para salir o ser atrapado ${ }^{10}$. El único que logra trascender el laberinto es Teseo, héroe-verdugo venido de afuera. En cambio, Asterión muere en su propio laberinto, atrapado por todos sus fantasmas. Esto nos permite preguntarnos, como ya lo hemos hecho antes: ¿representa la casa-laberinto nuestra estructura psíquica y Asterión-Minotauro las fuerzas inconscientes que la habitan? ¿Representa Asterión-Minotauro nuestras represiones, pulsiones y temores? ¿Quién nos podrá liberar de esas fuerzas inconscientes?

Dentro del laberinto psicológico, subyace la idea de un desdoblamiento del yo, perfilada en el mito de Narciso: un yo que se contempla y un yo que es contemplado. Se trata de la teoría del doble que

10. Puede verse en estos laberintos una estructura de caja china, como en los sueños borgesianos: uno dentro de otro: cuando creo que salgo de uno empiezo a entrar en otro. 
nos conduce al problema de la identidad mutable, reversible, intercambiable: hoy se es cobarde y mañana valiente, el muerto y el matador, el héroe y el traidor, el victimario y la víctima, es decir, el anverso y el reverso de la misma moneda. El común denominador de varios relatos centrados en la teoría del doble es el hecho de que uno de los personajes muere. Casi siempre, estas muertes son violentas. Como señala Ariel Dorfman: «Los personajes, perseguidor y perseguido, verdugo y víctima, se buscan en medio de laberintos y misterios, se comunican a través del lenguaje de los puñales, de las balas, del fuego. La muerte, para Borges, es casi siempre un asesinato, necesita de otro, presume otra mano y otro rostro»" . Esta doble identidad presupone un cierto sometimiento ante el otro y, nuevamente, se intercambian los papeles de víctima y victimario: en manos de Teseo, el victimario Asterión es víctima. En este sentido, el hombre que lleva la espada limpia de sangre en su mano se constituye en héroe: la espada representa la vida y la justicia para el pueblo, pero la muerte y a la vez la redención para Asterión, que nosotros hemos comenzado a querer y a identificarnos como víctima. El texto nos ha afectado.

\section{Sobre el carácter fantástico del texto}

Puede decirse que «La casa de Asterión» es un texto fantástico porque desde el puro inicio, como lectores, estamos involucrados: opera con alusiones, omisiones, enigmas y pistas que debemos seguir, es decir, nos implica y complica como lectores. En lugar de referirse desde el título al laberinto y al Minotauro, el texto fusiona un elemento familiar con otro extraño que nos distancia y nos hace preguntarnos quién es Asterión. El epígrafe sólo alude a la madre y al hijo: ¿y el padre?, ¿quién es?, ¿el rey? En el plano narrativo, el texto es todo un artificio, está armado a partir de un juego de voces: la tercera persona que abre (en el título y en el epígrafe) y que cierra (en

11. Ariel Dorfman. «Borges y la violencia americana», Imaginación y violencia en Améric a (Santıago de Chile: Universıtaria. 1970) 39. 
la comunicación de la muerte de Asterión) sirve de marco para que aparezca la voz en primera persona de Asterión, voz circunscrita.

Al principio, el texto nos distancia frente a la historia enigmática que nos va a of recer, después nos familiariza al sumergirnos en el mundo interior de Asterión con el que logra identificarnos y, al final, nos da un golpe trágico: Teseo ha matado a Asterión que posiblemente lo confunde con su esperado redentor. Con esto el texto no se deja adivinar-anticipar y rompe con la imagen tradicional del Teseo héroe liberador del pueblo y se construye la imagen de un Teseo verdugo de Asterión, con el que nosotros nos habíamos identificado y solidarizado en su pena y en su soledad. En este sentido, el texto de Borges vuelca el mito clásico y sus asociaciones tradicionales: nos desfamiliariza de la versión común, deforma lo didáctico para volverlo siniestro, como hace Hoffmann con El hombre de la arena: lo monstruoso del Minotauro nos lo hace familiar e íntimo. La imagen monstruosa sugerida-evocada por el título y el epígrafe es destruida por el monólogo de Asterión con quien nos identificamos. El ideal del héroe es destruido y reemplazado por uno nuevo, ahora victimado, dando origen al juego del héroe y el verdugo del que no terminamos de ver sus contornos e identificar dónde termina uno y comienza el otro.

La casa de Asterión no sólo representa al universo y el personaje al Minotauro, sino también la estructura psíquica con todas sus fuerzas inconscientes. Aunque Asterión afirme que no le interesa lo que un hombre pueda transmitir a otro por medio de la escritura, lo ansiado es el contacto humano. De acuerdo con la lógica de los textos de Borges, el victimario espera llegar a ser la víctima: se da una sustitución del Minotauro devorador de jóvenes por la imagen de un ser humanizado, desencantado, encerrado en la soledad de su singular existencia, que espera ser redimido, pero a la vez sacrificado. Asterión se siente un ser condenado a vivir en una circularidad opresora, mientras aguarda a su redentor que lo ayudará a superar el sinsentido de su vida. Interpreta la acción futura de su victimario desde un 
peculiar punto de vista donde la muerte es causa de redención: nadie se salva si no muere.

Las palabras de Teseo que cierran el texto no sólo revelan el desconcierto de éste ante la actitud que asume Asterión, sino que constituyen una metáfora del asombro de los hombres ante la imposibilidad de entender al otro, que se percibe diferente, extraño. Al cumplir Teseo con la voluntad del Minotauro, cumple con el destino de los hombres, en el sentido de que siempre están buscando al Redentor que los libere del laberinto terrenal y los purifique de la culpa: en el caso de Asterión, de la soledad más absoluta y de sí mismo en cuanto laberinto. En el mito clásico, Teseo es el héroe que salva a los seres humanos del monstruoso Minotauro. En la versión de Borges, Teseo es el héroe-redentor, no de los hombres, sino del propio Minotauro. Pero Teseo también es el verdugo.

\section{Maldigamos la verdad}

Si la verdad toda es imposible para quien habla — como sostiene Manuel Picado-, queda el decirla mal, mediodecirla o maldecir$\mathrm{la}^{12}$. Con esta licencia me voy a permitir balbucear algunas otras palabras. Una pregunta de la que me gustaría ensayar respuesta es: ¿el silencio sobre el padre se deberá a que, como representante de la Ley y del Bien del Estado, separó al hijo de la madre para ocultar la culpa original de Pasífae y su relación carnal con el toro? Si partimos de que el lenguaje es primordialmente evocativo, como lector me concierne averiguar qué evocan los términos Minotauro, toro, Pasífae y Minos en el texto y a qué cadena asociativa se inserta o a cuál da lugar. Esto me lleva a recordar la leyenda y el mito y aproximarme al texto desde una lectura intertextual: Minos, Radamantis y Sarpedón eran hijos de Zeus y de Europa, a la que Zeus raptó tras tomar forma de toro. Para resolver la cuestión de quién debía ser el rey de Creta,

12. Manuei Picado. “De curaciones ý enfermedades», Inscribir el Psicoanálisis, 9 (San José, enero-diciembre de 1999) 64 . 
Minos rogó a Poseidón que le enviase una víctima a la que sacrificar y el dios le envió un toro. Minos asumió el reino pero no quiso matar al toro. Airado, Poseidón hizo que la esposa de Minos, Pasífae, se enamorara del toro y de la unión de ambos nació el Minotauro.

El silencio sobre el padre en el texto de Borges se debe a esta falta originaria que desencadena la ira del dios del mar y a la relación carnal de Pasífae con el toro que debía ser sacrificado. Minos no sólo quiere reprimir a ese ser monstruoso, a ese otro y extraño que ha irrumpido desde su alcoba, sino que también desea ocultar su falta: confina al Minotauro en el laberinto y obliga a Atenas a pagar un tributo en vidas humanas para alimentar a la bestia. El laberinto se convierte, entonces, en el espacio de la represión y por ello lugar del inconsciente o lugar de las representaciones reprimidas. Con las víctimas sacrificadas al Minotauro se establece el círculo de la demanda que impedirá a Atenas conseguir su deseo: liberarse del Minotauro, que remite a liberarse de Minos. Teseo, como una de las víctimas ofrecidas a Asterión, lleva a cabo el deseo de su patria al eliminar a la bestia: Teseo se hace Deseo y de víctima pasa a victimario.

Cuando Teseo irrumpe en el laberinto y elimina a Asterión con la espada, no sólo vence a la bestia como aquello siniestro y espantable, sino que también supera las sinuosidades del laberinto, liberando las fuerzas del inconsciente. Este último trayecto se lleva a cabo por medio de la palabra cuando se lo comunica a Ariadna: «El Minotauro apenas se defendió». Con la muerte del Minotauro se acaba la Ley y el Bien del Estado que representaba Minos y se da inicio al reconocimiento de(l) Teseo-Deseo como héroe. Asterión ha sido aniquilado en el seno de la madre que es el laberinto.

En esa casa donde no hay un diván, Asterión está en lugar del analizante y el lector en lugar del analista: aquél habla-cuenta y el lector inscribe esa palabra en una historia y enlaza los acontecimientos de Asterión a otros antiguos, de tal modo que éste queda inscrito en una historia que le confiere a los acontecimientos actuales una posibilidad de sentido: la historia de Asterión la leemos desde el texto de 
la cultura cifrado en el mito del Minotauro y el laberinto. Establecer el sentido es referir el acontecimiento de hoy a todos los acontecimientos pasados y más allá, a un hipotético acontecimiento inicial que nunca se produjo: ese acontecimiento inicial constituye el acto incumplido de que todos nuestros actos involuntarios son sustitutos y nos indica que la significación de nuestros actos fallidos es una significación sexual ${ }^{13}$. Por eso el tema del padre es un asunto umbilicado en el texto, al igual que la muerte, porque está ocultando el asunto de la relación culposa de la madre con el toro que debía ser sacrificado: la madre se entrega a un toro cuyo ofertado principal debía ser un dios. Cuando Teseo elimina al Minotauro lo que hace es eliminar a Minos y al Tauro, al padre y a ese otro que lo representa.

El lector se habrá enterado de las varias funciones que cumple la casa en este texto de Borges. El término humaniza el mundo y el espacio donde ha sido recluido Asterión-Minotauro: hace más familiar y próxima la historia de lo que tradicionalmente ha sido concebido y registrado en el texto cultural como un monstruo. Funciona también como metonimia del mundo único e irrepetible del diferente que se cree superior por excluido y marginado: la autoridad del rey dispone expulsar de su casa-reino al hijo ilícito de la reina y ubicarlo en otro centro desde donde Asterión hace centro y convierte en marginal a los otros. También el espacio funciona como estructura psíquica de la que brotan los temores y fantasmas sobre el origen, el ser, el acontecer y el devenir de Asterión: no sólo basta plantear de dónde se viene y dónde se está siendo, sino lo que sucederá en el futuro, cómo será el otro mundo sin recodos y galerías sinuosas donde se espera al Otro. En este sentido, la casa-laberinto representa el camino del ser desde su origen hasta su fin último.

13. Juan David Nasıo. El placer de leer a Freud (Barcelona: Gedisa. 1996) 56-57. Una nota curiosa: Asterión-Mmotauro y la espada son símbolos solares $y$, por lo tanto, masculinos, mientras que la casa-laberinto no sólo son el centro del mundo e imagen del universo, sino que también remiten a la madre. al seno materno y al inconsciente. 


\section{Anexo}

\section{La casa de Asterión}

$Y$ la reina dio a luz un hijo que se llamó Asterión. Apolodoro: Biblioteca, III. I

Sé que me acusan de soberbia, y tal vez de misantropía, y tal vez de locura. Tales acusaciones (que yo castigaré a su debido tiempo) son irrisorias. Es verdad que no salgo de mi casa, pero también es verdad que sus puertas (cuyo número es infinito) ${ }^{14}$ están abiertas día y noche a los animales. Que entre el que quiera. No hallará pompas mujeriles aquí ni el bizarro aparato de los palacios, pero sí la quietud y la soledad. Asimismo hallará una casa como no hay otra en la faz de la tierra. (Mienten los que declaran que en Egipto hay una parecida). Hasta mis detractores admiten que no hay un solo mueble en la casa. Otra especie ridícula es que yo, Asterión, soy un prisionero. ¿Repetiré que no hay una puerta cerrada, añadiré que no hay una cerradura? Por lo demás, algún atardecer he pisado la calle; si antes de la noche volví, lo hice por el temor que me infundieron las caras de la plebe, caras desconocidas y aplanadas, como la mano abierta. Ya se había puesto el sol, pero el desvalido llanto de un niño y las toscas plegarias de la grey dijeron que me habían reconocido. La gente oraba, huía, se prosternaba; unos se encaramaban al estilóbato del templo de las Hachas, otros juntaban piedras. Alguno, creo, se ocultó bajo el mar. No en vano fue una reina mi madre; no puedo confundirme con el vulgo, aunque mi modestia lo quiera.

El hecho es que soy único. No me interesa lo que un hombre pueda transmitir a otros hombres; como el filósofo pienso que nada es comunicable por el arte de la escritura. Las enojosas y triviales minucias no tienen cabida en mi espíritu, que está capacitado para lo grande; jamás he retenido la diferencia entre una letra y otra. Cierta impaciencia generosa no ha consentido que yo aprendiera a leer. A veces lo deploro, porque las noches y los días son largos.

14. El original dice catorce, pero sobran motivos para inferir que. en boca de Asterión. ese adjetivo numeral vale por infinitos. 
Claro que no me faltan distracciones. Semejante al carnero (1แ1 " " " embestir corro por las galerías de piedra hasta rodar al suelo, marcialu. Mi. agazapo a la sombra de un aljibe o a la vuelta de un corredor y juego il (III' me buscan. Hay azoteas desde las que me dejo caer, hasta ensangrentarmic. A cualquier hora puedo jugar a estar dormido, con los ojos cerrados y li respiración poderosa. (A veces me duermo realmente, a veces ha cambiado el color del día cuando he abierto los ojos). Pero de tantos juegos el que prefiero es el de otro Asterión. Finjo que viene a visitarme y que yo le muestro la casa. Con grandes reverencias le digo: Ahora volvemos a la encrucijada anterior o Ahora desembocamos en otro patio o Bien decía yo que te gustaría la canaleta o Ahora verás una cisterna que se llenó de arena o Ya verás como el sótano se bifurca. A veces me equivoco y nos reímos buenamente los dos.

No sólo he imaginado esos juegos; también he meditado sobre la casa. Todas las partes de la casa están muchas veces, cualquier lugar es otro lugar. No hay un aljibe. un patio, un abrevadero, un pesebre; son catorce (son infinitos) los pesebres. abrevaderos, patios, aljibes. La casa es del tamaño del mundo; mejor dicho, es el mundo. Sin embargo, a fuerza de fatigar patios con un aljibe y polvorientas galerías de piedra gris he alcanzado la calle y he visto el templo de las Hachas y el mar. Eso no lo entendí hasta que una visión de la noche me reveló que también son catorce [son infinitos] los mares y los templos. Todo está muchas veces, catorce veces, pero dos cosas hay en el mundo que parecen estar una sola vez: arriba, el intrincado sol; abajo, Asterión. Quizás yo he creado las estrellas y el sol y la enorme casa, pero ya no me acuerdo.

Cada nueve años entran en la casa nueve hombres para que yo los libre de todo mal. Oigo sus pasos o su voz en el fondo de las galerías de piedra y corro alegremente a buscarlos. La ceremonia dura pocos minutos. Uno tras otro caen sin que yo me ensangriente las manos. Donde cayeron, quedan, y los cadáveres ayudan a distinguir una galería de las otras. Ignoro quienes son, pero sé que uno de ellos profetizó, en la hora de su muerte que alguna vez llegaría mi redentor. Desde entonces no me duele la soledad, porque sé que vive mi redentor. y al fin se levantará sobre el polvo. Si mi oído alcanzara todos los rumores del mundo. yo percibiría sus pasos. Ojalá me lleve a un lugar con menos galerías y menos puertas. ¿Cómo será mi redentor?. me pregunto. ¿Será un toro o un hombre? ¿O será como yo? 
El sol de la mañana reverberó en la espada de bronce. Ya no quedaba ni un vestigio de sangre. defendió.

— ¿Lo creerás, Ariadna? — dijo Teseo-. El Minotauro apenas se 